\title{
ABSCESSO PIOGÊNICO DO FÍGADO E ESQUISTOSSOMOSE MANSÔNICA: OBSERVAÇÕES NO ESTADO DO ESPÍRITO SANTO
}

\author{
Carlos Musso, Fausto E.L. Pereira, Roberto V. Dettogni e \\ Marco A.B. Ferreira
}

\begin{abstract}
Recentemente, foi demonstrado que a forma toxêmica da esquistossomose mansônica em crianças pode ser fator predisponente para abscesso piogênico do figado (APF). Como no Estado do Espírito Santo, a esquistossomose é endêmica em grande parte do estado e os APF são freqüentemente diagnosticados no Hospital Infantil Nossa Senhora da Glória de Vitória, realizou-se revisão dos casos de APF diagnosticados entre maio de 1991 e abril de 1994, com a finalidade de identificar-se os casos com infecção esquistossomótica e a sua procedência. Identificaram-se 65 casos de APF e 39 apresentavam exame de fezes registrado no prontuário, sendo 3 positivos para Schistosoma mansoni e 29 positivos para outros belmintos intestinais, principalmente áscaris e tricocéfalo. A procedência dos pacientes mostrou que $7(10,6 \%)$ eram provenientes de zona endêmica da esquistossomose. A associação APF e esquistossomose mostrou-se pequena e não há grande sobreposição na distribuição geogrä́ica das duas doenças. Por outro lado a alta prevalência de infecção por outros belmintos intestinais e o grande número de abscessos piogênicos criptogenéticos diagnosticados, faz pensar que as infecções belminticas com larias que podem migrar para o figado e formar granulomas, possam também ser um fator predisponente para o abscesso bepático em crianças.
\end{abstract}

Palauras-chaves: Abscesso bepático. Esquistossomose mansônica. Helmintíases.

Recentemente, Lambertucci e cols ${ }^{3}$ e Teixeira ${ }^{5}$ levantaram a hipótese de que a infecção esquistossomótica aguda poderia ser um fator predisponente para o desenvolvimento de abscesso piogênico do fígado em crianças. Os autores relataram, respectivamente, três e dez casos em crianças nas quais a infecç̧ão esquistossomótica aguda estava presente (forma toxêmica). Os mesmos autores induziram abscessos hepáticos por inoculação intravenosa de estafilococos em camundongos experimentalmente infectados com Schistosoma mansoni, fato não observado em animais controle sem infecção esquistossomótica.

A esquistossomose mansônica é endêmica no Estado do Espírito Santo (na região oeste, cortada pelo Rio Doce) e abscessos piogênicos do fígado em crianças são freqüentemente diagnosticados no Hospital Infantil Nossa Senhora da Glória em Vitória. Dettogni e cols ${ }^{1}$

Serviços de Patologia e de Cirurgia do Hospital Infantil Nossa Senhora da Glória, Vitória, ES.

Endereço para correpondência: Dr. Fausto E.L. Pereira. Núcleo de Doenças Infecciosas. Centro Biomédico/UFES. Av. Marechal Campos 1468, 29040-090 Vitória, ES.

Recebido para publicação em 10/08/95. relataram 30 casos diagnosticados entre junho de 1981 a dezembro de 1985 , dos quais $40 \%$ não apresentavam um fator predisponente identificável. Por essa razão nos propusemos a estudar a ocorrência de infecção esquistossomótica em crianças portadoras de abscesso piogênico do fígado e a procedência de cada caso no sentido de verificar se há sobreposição na distribuição geográfica das duas doenças.

\section{MATERIAL E MÉTODOS}

Foi feita uma revisão dos prontuários dos pacientes internados no Hospital Infantil Nossa Senhora da Glória (HINSG) em Vitória, no período compreendido entre maio de 1991 e abril de 1994, sendo separados casos nos quais havia um diagnóstico de abscesso hepático. $\mathrm{O}$ HINSG é o único hospital pediátrico de referência no estado, atendendo crianças de todos os municípios, representando sua clientela boa amostragem da população pediátrica que procura cuidados médicos que requerem internação hospitalar no Espírito Santo.

$\mathrm{Na}$ revisão dos prontuários, foram anotados os dados sobre a procedência e sobre exa me 
Musso C, Pereira FEL, Dettogni RV, Ferreira MAB. Abcesso piogênico do figado e esquistossomose mansônica: observações no Estado do Espirito Santo. Revista da Sociedade Brasileira de Medicina Tropical 29:359-362, jul-ago, 1996.

parasitológico de fezes. Os exames parasitológicos de fezes (um para cada caso) foram realizados no laboratório de análises do Hospital, por métodos rotineiros, que não incluem métodos específicos para pesquisa de ovos de Schistosoma mansoni. Os dados sôbre a procedência foram lançados em um mapa do Estado do Espírito Santo, no qual estão indicados os limites dos municípios, as áreas endêmicas de esquistossomose e os locais onde os caramujos não infectados tem sido identificados (Figura 1).

\section{RESULTADOS}

Entre os prontuários dos pacientes internados no HINSG no período de maio de 1991 a abril de 1994 encontraram-se 65 casos de abscesso piogênico do fígado (média de idade de 7,6 $\pm 3,7$ anos, variando entre 1 e 14 anos e relação masculino/feminino de 2,6:1). Em todos os casos o diagnóstico foi onfirmado pela ultrassonografia abdominal ou no ato cirúrgico para drenagem ou na necrópsia. Como fatores predisponentes havia

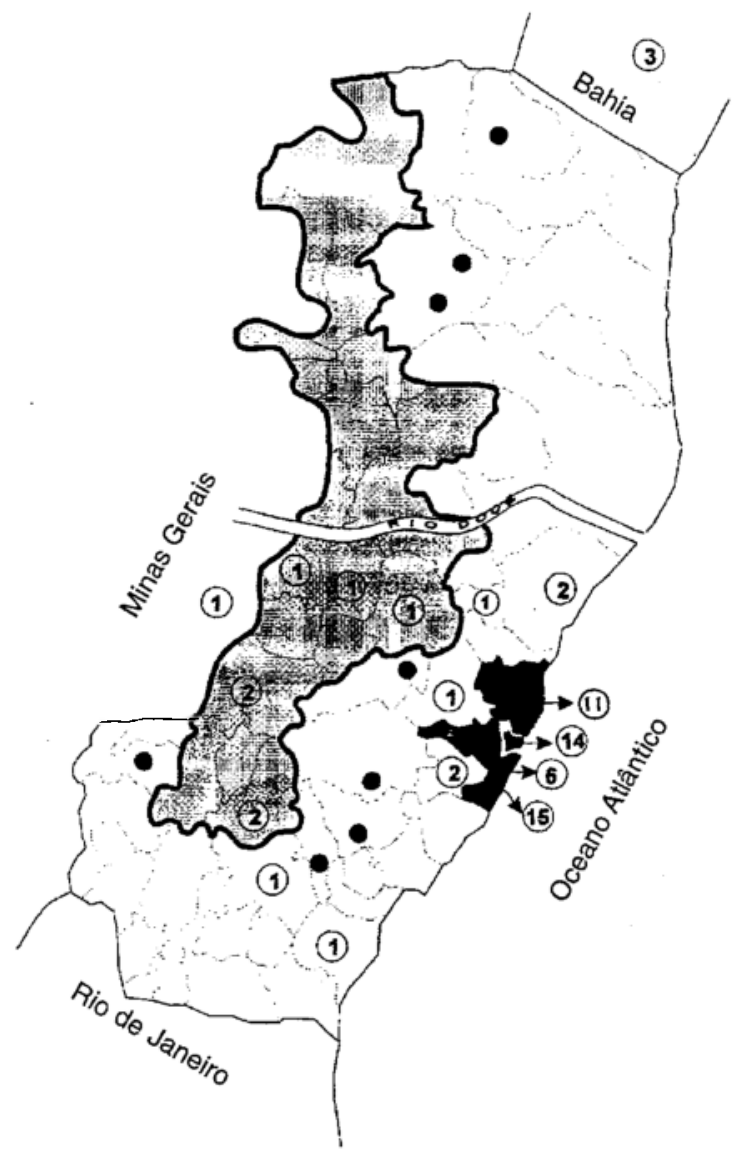

Figura 1 - Mapa do Estado do Espirito Santo indicando a procedência de 65 casos de abscesso piogênico do figado diagnosticados no Hospital Infantil de Vitória (periodo maio 91/abril 94). Os nümeros 120s circulos indicam o número de casos procedentes de cada município. A área cinza clara, delimitada por linba grossa, representa a área endemica para esquistossomose no Estado e a área mais escura delimita a regiāo metropolitana da Grande Vitória. Os círculos cbeios indicam äreas onde caramujos não infectados com S. mansoni têm sido detectados (o mapa com a distribuição da esquistossomose foi cedido pela Fundação Nacional de Saúde, Vitória). 
Musso C, Pereira FEL, Dettogni RV, Ferreira MAB. Abcesso piogênico do fígado e esquistossomose mansônica: observações no Estado do Espírito Santo. Revista da Sociedade Brasileira de Medicina Tropical 29:359-362, jul-ago, 1996.

a presença de infecçâo sistêmica a partir de lesões cutâneas em 23, obstrução biliar por áscaris em seis e trauma em três, mas em 30 $(41,6 \%)$ casos um fator predisponente não foi identificado (em três casos não havia informações sobre possíveis lesões ou fatores predisponentes).

Havia relato de realização de hemocultura em 29 casos e cultura do material do abscesso colhido por punção externa ou durante a cirurgia em 23 casos; dessas culturas 25 resultaram positivas, sendo 24 para Stapbyloccocus aureus e uma para Escberichia coli: em nenhum caso houve pesquisa de anaeróbios. Em nenhum dos materiais colhidos nas punções ou na cirurgia houve identificação de Entamoeba bistolytica.

Os dados dos exames de fezes, anotados em 39 prontuários, mostraram três casos positivos para Scbistosoma mansoni, com presença de poucos ovos e 26 positivos para outros helmintos, principalmente áscaris, tricocéfalo, estrongilóide e necator. Entamoeba bistolytica (cistos) só foi identificada em um caso. Nos casos em que foi realizada biópsia hepática (quatro casos) ou necrópsia (quatro casos), não foram detectadas lesões produzidas pelo Schistosoma mansoni.

A procedência dos pacientes com abscesso piogênico do fígado mostrou que sete casos eram provenientes de municípios localizados em zona endêmica para Schistosoma mansoni. mas a grande maioria ( 46 casos) era proveniente da região da grande Vitória (formada pelos municípios de Vitória, Vila Velha, Serra e Cariacica (Figura 1), onde a esquistossomose não é endêmica. Dos sete casos procedentes de localidades endêmicas, quatro tiveram exame de fezes negativo para Schistosoma mansoni.

\section{DISCUSSÃO}

Esses resultados confirmam que a freqüência de abscessos piogênicos do fígado em crianças, diagnosticados em Vitória (ES), é grande, já que nos países desenvolvidos a doença é considerada pouco freqüente, ocorrendo geralmente em crianças com deficiência imunitária² .

O número de casos em que havia presença de ovos de Schistosoma mansoni nas fezes foi pequeno $(3 / 39$ ou $7,6 \%)$. Essa freqüência, pode não ser real, já que havia apenas um exar ? de fezes e sem método específico para identificação de ovos de Schistosoma mansoni, mas não difere significativamente da freqüência da parasitose em crianças observada em um inquérito coprológico feito pela SUCAM em 1975 em todos os municípios do estado (prevalência média de 5\% entre escolares do primeiro grau; dados obtidos na Fundação Nacional de Saúde, Vitória).

A distribuição da procedência dos casos de abscesso piogênico do fígado, demonstrada na Figura 1, mostra que a grande maioria é procedente da região da Grande Vitória, onde caramujos infectados com o Scbistosoma mansoni não têm sido encontrados. Apenas sete casos eram procedentes dos municípios onde a esquistossomose é endêmica e entre esses, houve quatro casos em que o exame de fezes foi negativo para o Scbistosoma mansoni. De qualquer forma, os dados parecem indicar não haver maior freqüência de casos de abscesso piogênico do fígado em crianças provenientes das regiões onde a esquistossomose mansônica é endêmica no Espírito Santo.

Essas observaçôes não sugerem que a infecção pelo Schistosoma mansoni seja um fator predisponente importante para o abscesso hepático em crianças. É possivel que, conforme demonstraram Lambertucci e $\operatorname{cols}^{3} \mathrm{e}$ Teixeira $^{5}$, a associação seja freqüente somente com a forma toxêmica da doença, a qual é menos freqüente nas zonas endêmicas.

A maioria dos casos de abscesso piogênico do fígado aqui relatados foi proveniente da periferia urbana da Grande Vitória, onde as condiçôes de higiene são precárias, sendo alto o risco para infecções helmínticas, inclusive por Toxocara canis, devido à grande população canina existente. De fato, infecção helmíntica intestinal por áscaris, tricocéfalo, estrongilóide e ancilostomídeos ocorreu em $66,6 \%$ dos casos em que um exame de fezes estava anotado no prontuário. Acreditamos que infecções helminticas, especialmente as que produzem larvas migrantes que podem passar pelo fígado, possam também predispor ao abscesso piogênico do fígado por mecanismos semelhantes aos propostos por Lambertucci e $\operatorname{cols}^{3}$ e por Teixeira para o Scbistosoma mansoni: podem produzir modulação da resposta imunitária e os granulomas em torno da larva migrante (ou de seus antígenos) podem funcionar como lesão localizadora de bactérias no fígado. Essa hipótese foi levantada por Lambertucci e cols ${ }^{4}$ baseados em 
Musso C, Pereira FEL, Dettogni RV, Ferreira MAB. Abcesso piogênico do fígado e esquistossomose mansônica: observaçōes no Estado do Espirito Santo. Revista da Sociedade Brasileira de Medicina Tropical 29:359-362, jul-ago, 1996.

observações feitas em Belo Horizonte, MG, onde verificaram alta freqüencia de infecção helmíntica em casos de abscesso piogênico do fígado.

\section{SUMMARY}

A possible association of the acute toxaemic form of schistosomiasis and pyogenic liner abscess (PLA) bas been recently suggested. As in the west of the Espirito Santo state schistosomiasis is endemic and PLA are frequently diagnosed in the Children's Hospital of Vitoria we reviewed the records of the Hospital during the period from May 1991 to April 1993 to: a) iddentify all cases of PLA in which Schistosoma mansoni infection was present and $b$ ) annotate the procedence of each case to verify if there is an association of the two diseases. 65 cases of PLA were recorded and 39 bad the result of a stool examination, being three positive for Schistosoma mansoni $(7,6 \%)$ and 26 for other belmintb (mainly Ascaris and Trichocepbalus). The procedence of the patients showed that only 7 $(10,7 \%)$ came from endemic areas. These results show that an asociation of Schistosoma mansoni infection and PLA was not significative in the country, where the acute toxaemic form is not frequent. The great majority of PLA in this study came from the urban periphery of Vitoria, where transmission of schistosomiasis does not occur but intestinal belminth infections are extremely frequent. As $40 \%$ of these PLA were criptogenetic it is possible that the immunomodulation induced by intestinal parasites and the liver granulomas produced by the larvae of these belmintbs would be predisposing factors for pyogenic liver abscess.

Key-words: Liver abscess. Schistosomiasis. Helmintb infections.

\section{REFEREANCIAS BIBLIOGRÁFICAS}

1. Dettogni RV, Ferreira MAB, Freschiani MM, Musso C. Abscesso hepático piogênico na criança. Jornal de Pediatria 64:415-419,1988.

2. Kaplan SL. Pyogenic liver abscess. In: Feigin RD, Cherry JD (eds) Textbook of Pediatrics Infectious Diseases. $3^{\text {rd }}$ edition, WB Saunders Co, Philadelphia, p702-705, 1992.

3. Lambertucci JR, Teixeira R, Navarro MMM, Coelho PMZ, Ferreira MD. Liver abscess and schistosomiasis. A new asociation. Revista da Sociedade Brasileira de Medicina Tropical 23:239240,1990 .

4. Lambertucci JR, Teixeira R, Pereira FAS, Brant CQ, Pinto LW. Abscesso piogênico do figado: análise de 50 casos. Revista da Sociedade Brasileira de Medicina Tropical 24(supl 1): 83, 1991.

5. Teixeira R. Abscesso piogênico do fígado e esquistossomose mansônica, forma aguda: estudo clínico-experimental. Tese de Mestrado. Faculdade de Medicina da Universidade Federal de Minas Gerais, Belo Horizonte, MG, 1994. 